\title{
A fool's mission? A test of three common assumptions in dental metric analyses
}

Brian E. Hemphill

Department of Anthropology, 405A Bunnell Hall, University of Alaska, Fairbanks, Fairbanks, AK 99775-7720

Keywords: Morphogenetic Fields, Ontogenetic Canalization, Sex Dimorphism

ABSTRACT Three aspects of metric variation in the permanent dentition of humans are often simply accepted as true. The first is that formation of the permanent dentition occurs within morphogenetic fields broadly associated with tooth type and jaw. The second is that dental development of among females is characterized by a higher degree of ontogenetic buffering relative to males. The third is that expression of sex dimorphism in permanent tooth size is expressed uniformly among wellnourished human populations. This study tests these assumptions through an examination of mesiodistal and buccolingual dimensions of all non-canine permanent teeth, except third molars, among 2,709 living individuals of 15 ethnic groups from South Asia. With sexes pooled, only one in four contrasts of variance among key versus distal teeth within dental fields are significantly heterogeneous, while one in four contrasts yield higher levels of variance among key teeth relative to their distal counterparts within a dental field. Such results weaken considerably orthodox applications of Butler's dental field theory. When samples are

Over the last 70 years a consensus has emerged that dental development in humans is characterized by a series of developmental fields that correspond broadly to tooth type by jaw (Butler 1939; Dahlberg 1945, 1951), that odontogenesis is marked by a greater degree of developmental buffering, or "canalization," among females relative to males (Garn et al. 1965, 1966; Nichol et al. 1984; Niswander \& Chung 1965), and that expression of sex dimorphism is uniformly expressed across adequately nourished human populations (Kieser et al. 1985). This study tests these assumptions through assessment of mesiodistal and buccolingual dimensions of all noncanine permanent teeth except third molars among 2,709 living individuals of 15 ethnic groups from South Asia. the unit of analysis, male samples are marked by fewer dental fields with significantly heterogeneous levels of variance between key and distal members, while males and females are affected equally by significantly heterogeneous variation between key and distal members when dental fields are the unit of analysis. Such results suggest males and females are equally buffered against environmental perturbations that affect odontometric variation. One-way ANOVA indicates that a tooth's position within a dental field accounts for $15.5 \%$ to $23.1 \%$ of the observed variation in tooth size, while two-way ANOVA reveals that when sex is added as a second factor, the percentage of variance in tooth size explained increases from $16.7 \%$ to $30.8 \%$, an improvement of $27.2 \%$. Such results indicate sex dimorphism in tooth size varies in both patterning and in magnitude among these samples, thereby explaining why discriminant functions developed for one population often perform more poorly when applied to other populations.

\section{MATERIALS AND METHODS}

Dental casts were collected from 2,709 living individuals with informed consent of 15 ethnic groups from the Hindu Kush/Karakoram Highlands of northern Pakistan, the northern periphery of the Indus Valley of Pakistan, Gujarat State of northwestern peninsular India, and Andhra Pradesh State of southeastern India (Fig. 1). Of these, some 2,455 individuals (1,087 Females, 1,368 Males) are represented by casts for both upper and lower dentitions. Mesiodistal tooth lengths and buccolingual tooth breadths were measured for all teeth, except third molars using standard odentometric procedures (Moorrees, 1957). Kolmogorov-Smirnov tests were used to determine whether

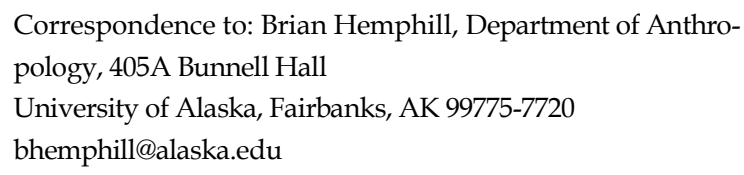




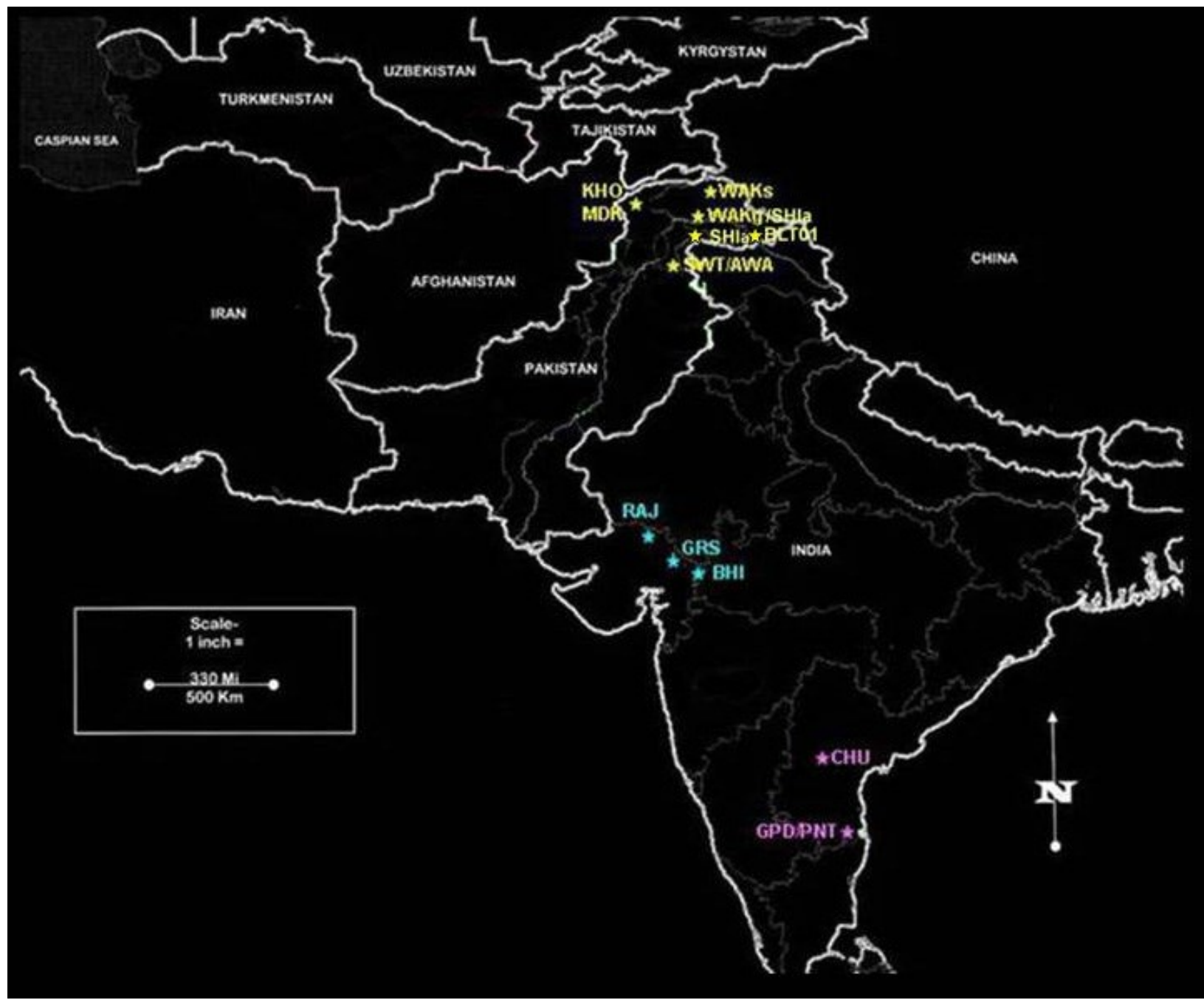

Fig. 1. Location of the samples used in the study. Abbreviations are from Table 1.

variable distributions by sex and by sample depart significantly from normality. Antemortem tooth loss, dental pathology and casting defects preclude some measurements from being collected. EM estimation (Dempster et al., 1977) was used to estimate missing values by sex and by sample. No more than three of the 28 variables $(10.7 \%)$ were estimated by individual. Teeth within incisor, premolar and molar dental fields were separated into "key" and "distal" members by jaw. Standard descriptive statistics were calculated for each variable. Heterogeneity of variance between key and distal members was tested with Bartlett's chisquare (Snedecor and Cochran, 1989) and variances were compared to test for the expected pattern of higher variance for the distal member within each morphogenetic field, except for the mandibular incisors for which Dahlberg $(1945,1951)$ maintained that the morphogenetic field was reversed, such that LI2 is considered the key tooth and LI1 the distal tooth. One-way ANOVA was used to test for the impact of position within a dental field upon tooth size in both sex-pooled and sex-segregated samples by ethnic group. Sexpooled samples were further tested with two-way ANOVA to determine the impacts of position and sex by ethnic group. Relative contributions of sex to position were rank ordered to illustrate differences between samples in the expression of sex dimorphism.

\section{RESULTS}

Kolmogorov-Smirnov tests reveal that mesiodistal lengths and buccolingual breadths for males and females of all 15 samples are distributed normally. Of the 2,455 individuals represented by 


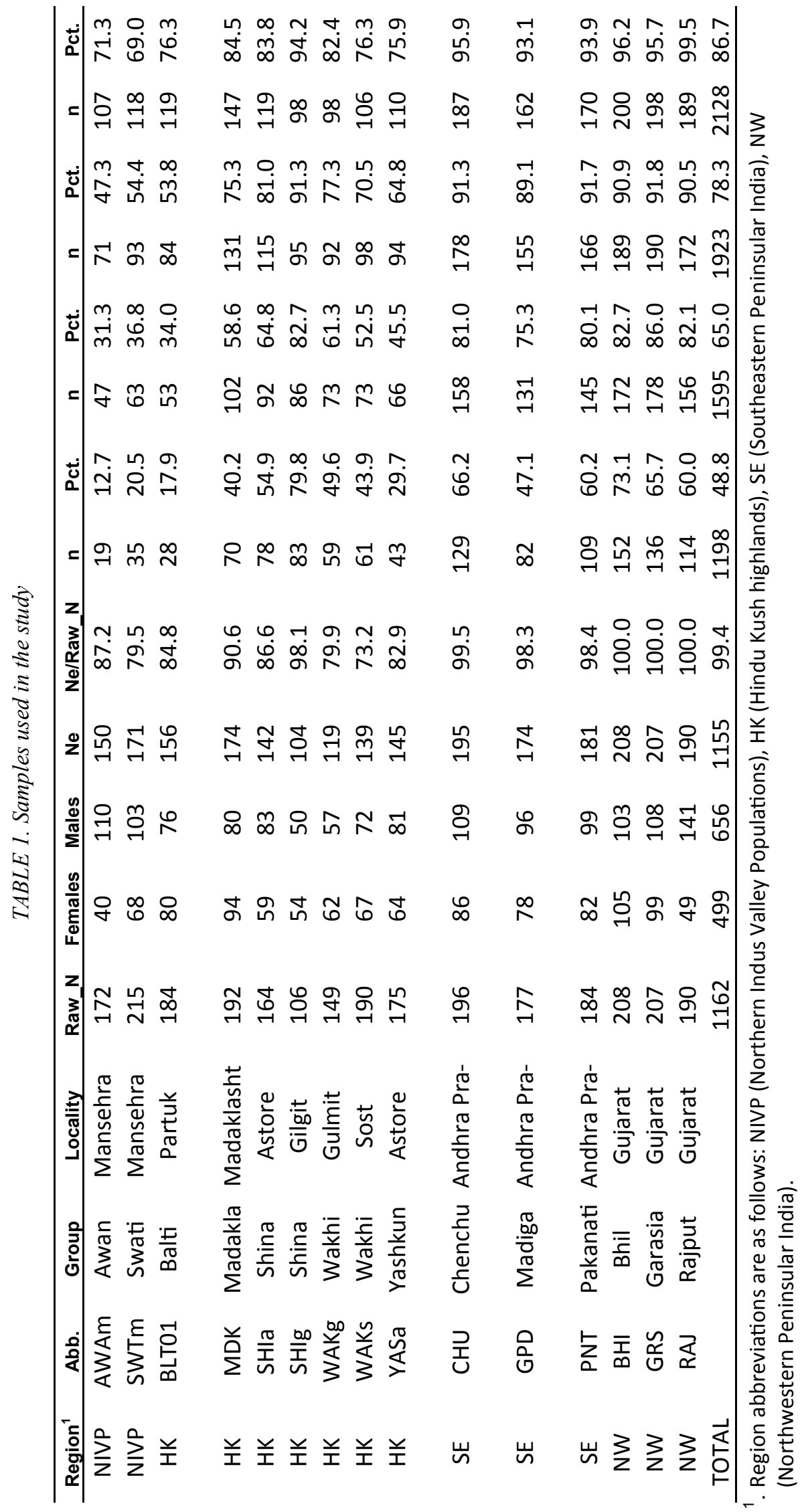




\section{Significant Differences (Sexes Pooled)}

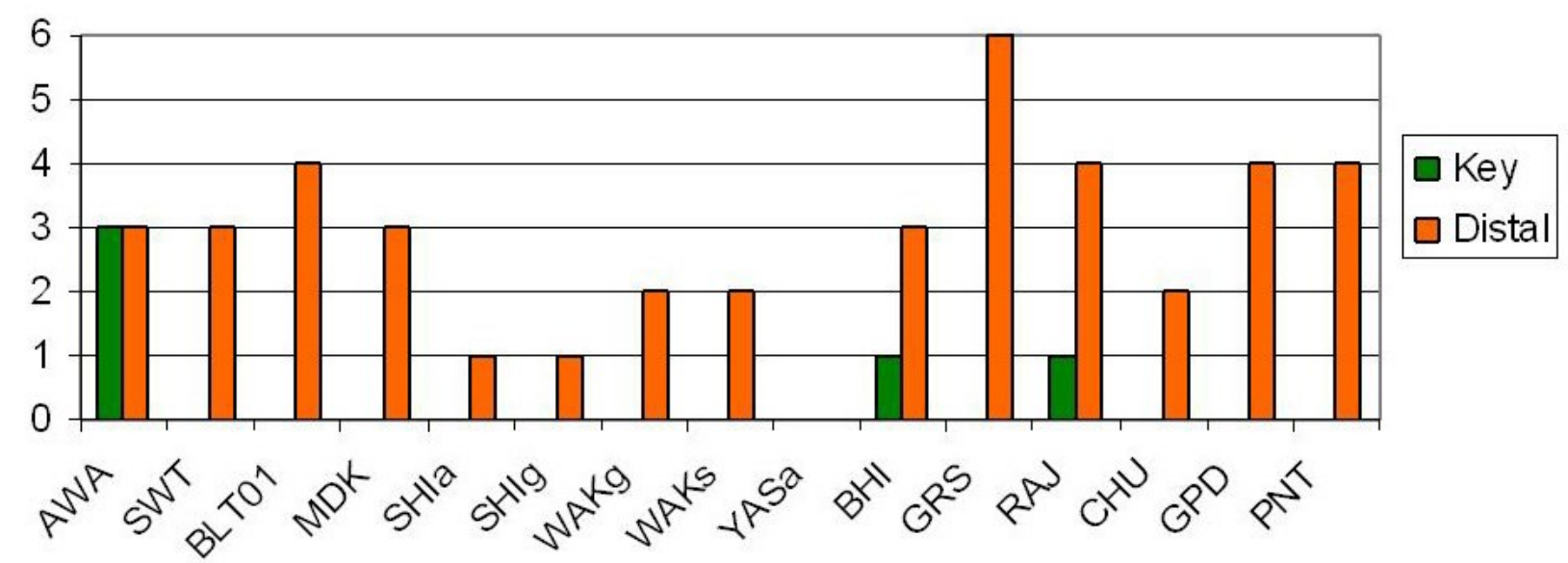

Fig. 2. Number of significant differences in variance between key and distal members of a dental field by position with sexes pooled.

casts for both dentitions only 1,198 (48.8\%) are represented by all 28 variables. Estimation of missing values improved the number of individuals with complete data from 1,595 (65.0\%), to 1,923 (78.3\%), to $2,128(86.7 \%)$ when 1,2 , and 3 variables were estimated, respectively (Table 1 ).

Bartlett's chi-square reveals that just over onefourth $(47 / 180=26.11 \%)$ of contrasts of variance between key and distal members of a dental field exhibit significant heterogeneity of variance. The number of significant differences by sample averages 3.13 out of the 12 fields $(26.08 \%)$ and ranges from a high of six fields among Awans and Garasias to a low of zero among the Yashkuns of Astore. When instances of significant heterogeneity of variance within dental fields are examined to determine whether this heterogeneity is driven by higher variance in key teeth versus higher variances in distal teeth, expectations of dental field theory are resoundingly confirmed. As expected, the vast majority $(42 / 47=89.36 \%)$ of cases involve higher variance for the distal member of a dental field (Fig. 2). In fact, instances of significantly higher variances among key teeth occur among members of only three of the ethnic groups considered here. These include Awans, Bhils, and Rajputs.

A situation in which the amount of variance among key members of a dental field exceed that found among their distal counterparts represents a reversal of dental field theory expectations. Examination of levels of variance reveals some 46 instances of reversal, accounting for just over onefourth of all comparisons $(46 / 180=25.56 \%)$. The number of reversals runs from a high of seven $(58.33 \%)$ among Shinas from Gilgit (SHIg) to lows of a single reversal among Garasias (GRS) and Gompadhomptis Madigas (GPD) (Fig. 3). Further examination indicates that while all non-canine dental fields of both jaws are affected, reversals are by far most common among the mandibular incisors (LI2>LI1) where two-thirds of all contrasts yielded reversals $(20 / 30=66.7 \%)$. Reversals are also common among mandibular molars $(9 / 30=$ $30.0 \%)$, are less common among maxillary incisors $(6 / 30=20.0 \%)$ as well as among mandibular $(5 / 30=16.67 \%)$ and maxillary premolars $(5 / 30=$ $16.67 \%)$, and are rarest among maxillary molars $(1 / 30=3.33 \%)$.

Analysis of variance indicates that position within a dental field contributes substantially to the percentage of variance explained in tooth size (Fig. 4). Across all 15 samples position alone accounts for nearly $20 \%$ of the variance in tooth size within a dental field, ranging from highs of $23.08 \%$ and $22.92 \%$ among Bhils and Chenchus to a low of $15.47 \%$ among the Wakhis of Gulmit.

Bartlett's chi-square (Fig. 5) reveals that males are marked by a fewer number of dental fields with significantly heterogeneous levels of variance 


\section{Reversals \\ (Sexes Pooled)}

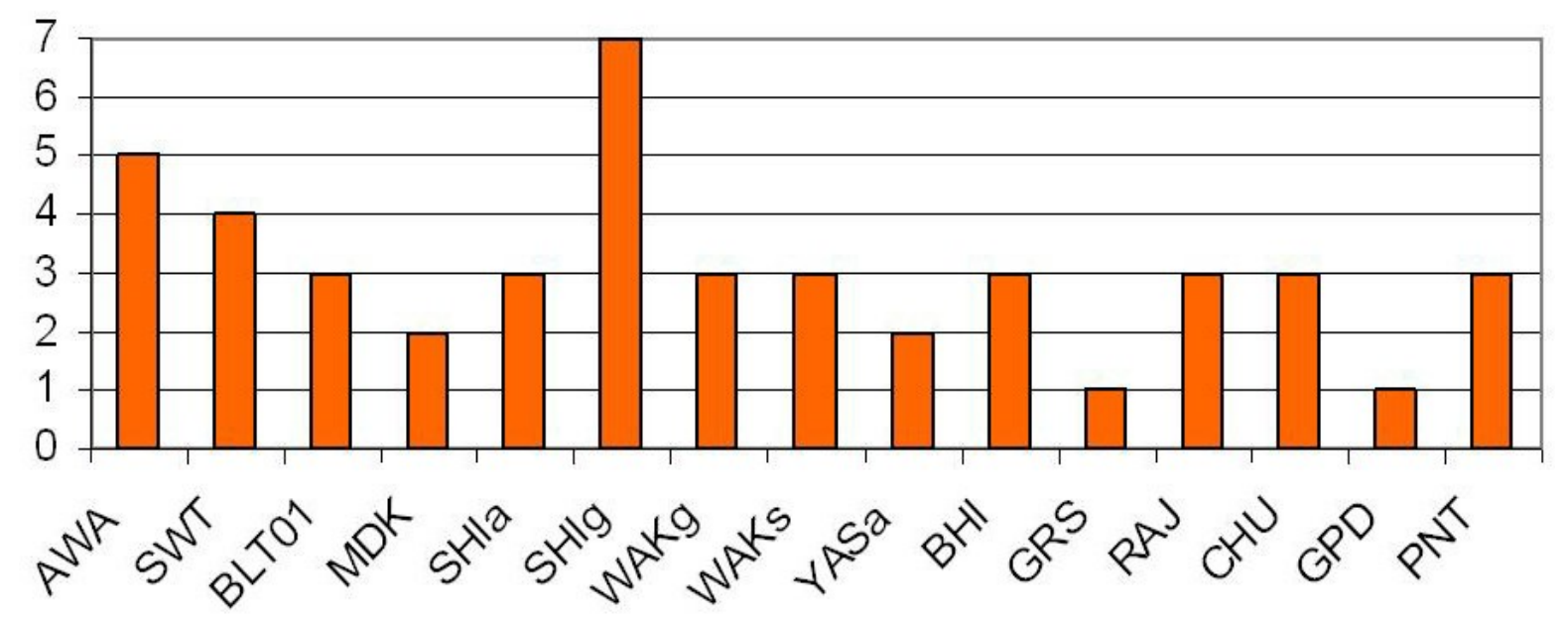

Fig 3. Number of reversals in relative variance between key and distal members of a dental field with sexes pooled.

between key and distal member, for significant heterogeneity occurs in only three of the 15 samples $(20.0 \%)$, while females are marked by equivalent or higher numbers of reversals in 12 of the 15 samples $(80.0 \%)$. When heterogeneity of variance is considered by dental field across all samples, Bartlett's chi-square identifies 68 of 360 (18.89\%) contrasts as exhibiting significantly heterogeneous levels of variance. Of these, 35 occur among males and 33 occur among females, indicating that males and females are marked by nearly identical numbers of significantly heterogeneous contrasts with regard to variance.

Examination of the patterning of variance among key and distal teeth within dental fields reveals that somewhat more than one-fourth $(99 / 360=27.5 \%)$ are marked by a reversal in which variance is greater among key teeth than their distal counterparts (Fig. 6). When considered by sex, males are more often affected by reversals $(31.11 \%)$ than females $(23.89 \%)$. In fact, males exhibit a marked increase $(30.23 \%)$ relative to that observed among females. When considered by sample, reversal prevalence is greater among males for only six of the 15 samples. This means that, contrary to expectations, males more often exhibit variance reversals than females overall, while in marginal support of expectations, females have a higher or equivalent number of dental fields marked by variance reversals than males in nine $(60 \%)$ of the 15 samples.

Analysis of variance has already indicated that a tooth's position within a dental field accounts for $15.5 \%$ to $23.1 \%$ of the variance in size across the 15 samples (Fig. 4). When this relationship is further explored by sex it is clear the influence of sex on the relative size of key and distal members within dental fields differs markedly (Fig. 7). In 11 samples, the average contribution of position is greater among females, while in the remaining four the contribution is greater among males. In some samples, such as the Awans (4.82\%) Swatis (6.3\%) and Baltis (4.74\%) this difference is well-marked, but in others, such as the Bhils $(0.01 \%)$, the greater contribution of position among females is minimal. In fact, the opposite pattern may also be discerned, where among some samples the difference between the sexes is well-marked, but is greater among males than females, such as among the Wakhis of Gulmit (5.3\%), or is but minimal as is the case for Pakanatis $(0.14 \%)$. Such findings indicate that sex contributes substantially, but differently by sample, to relative tooth size between key and distal members of the same morphogenetic field. 


\section{Contribution by Position}

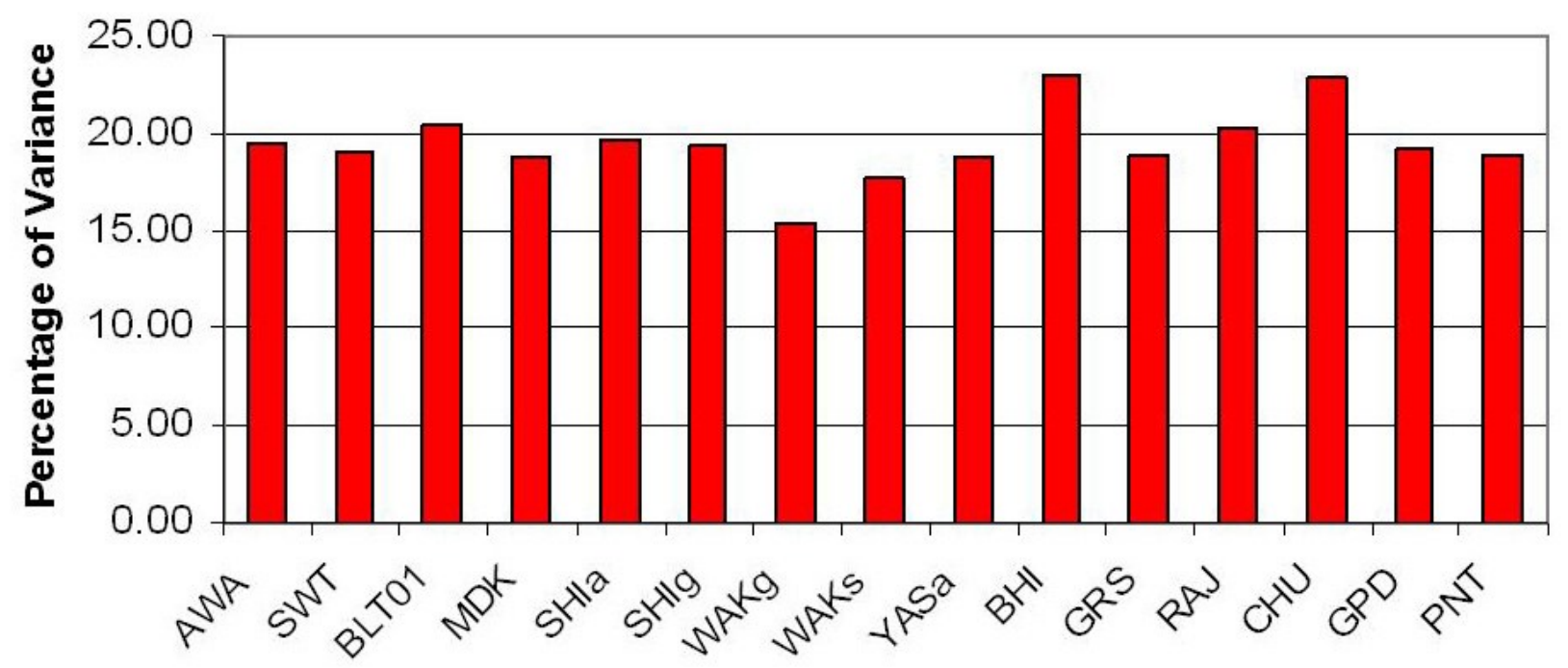

Fig. 4. Average contribution by position in accounting for variance in tooth size between key and distal members of a dental field with sexes pooled.

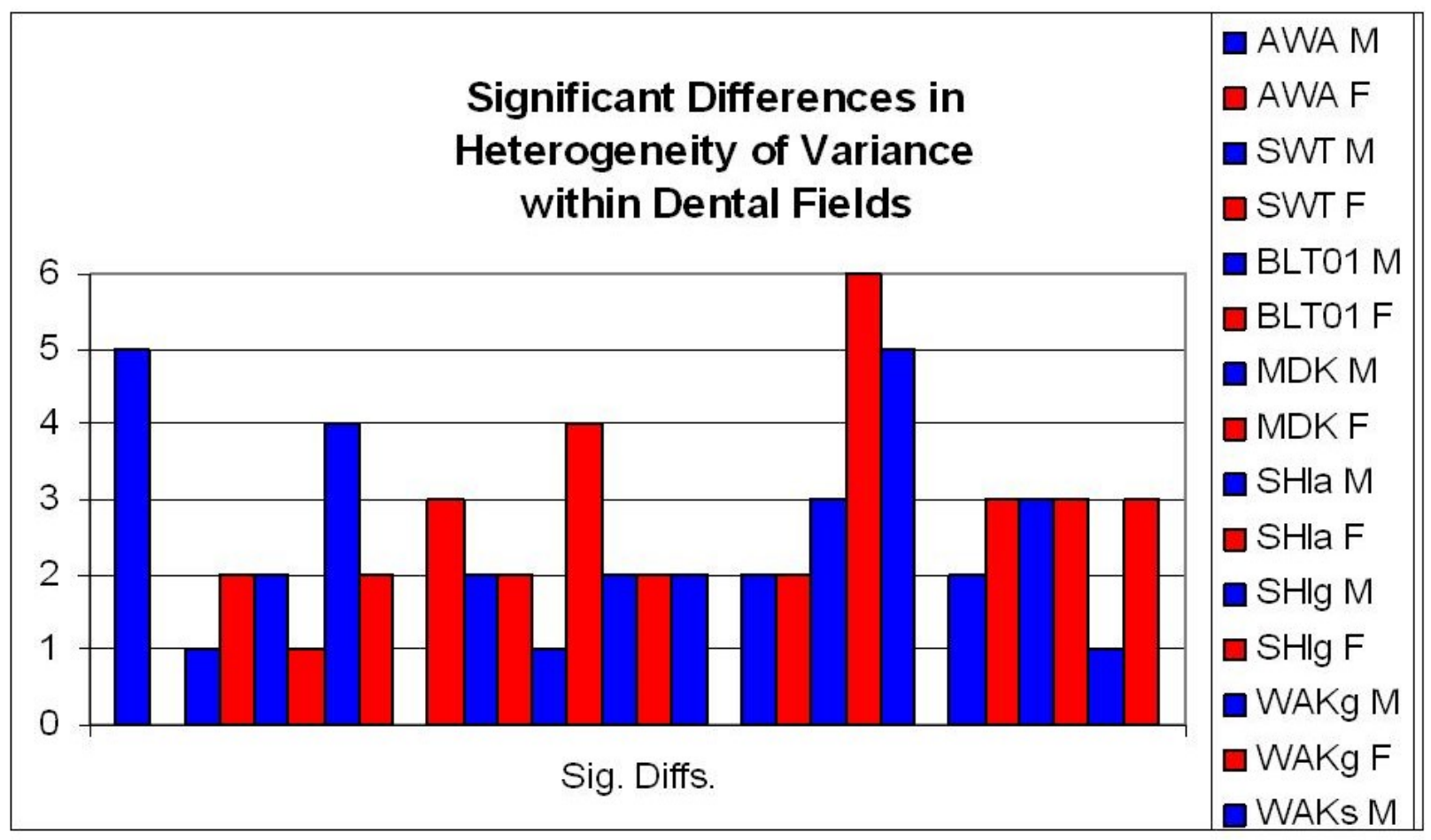

Fig. 5. Number of dental fields in which there are significantly different levels of variance between the key and distal member. 


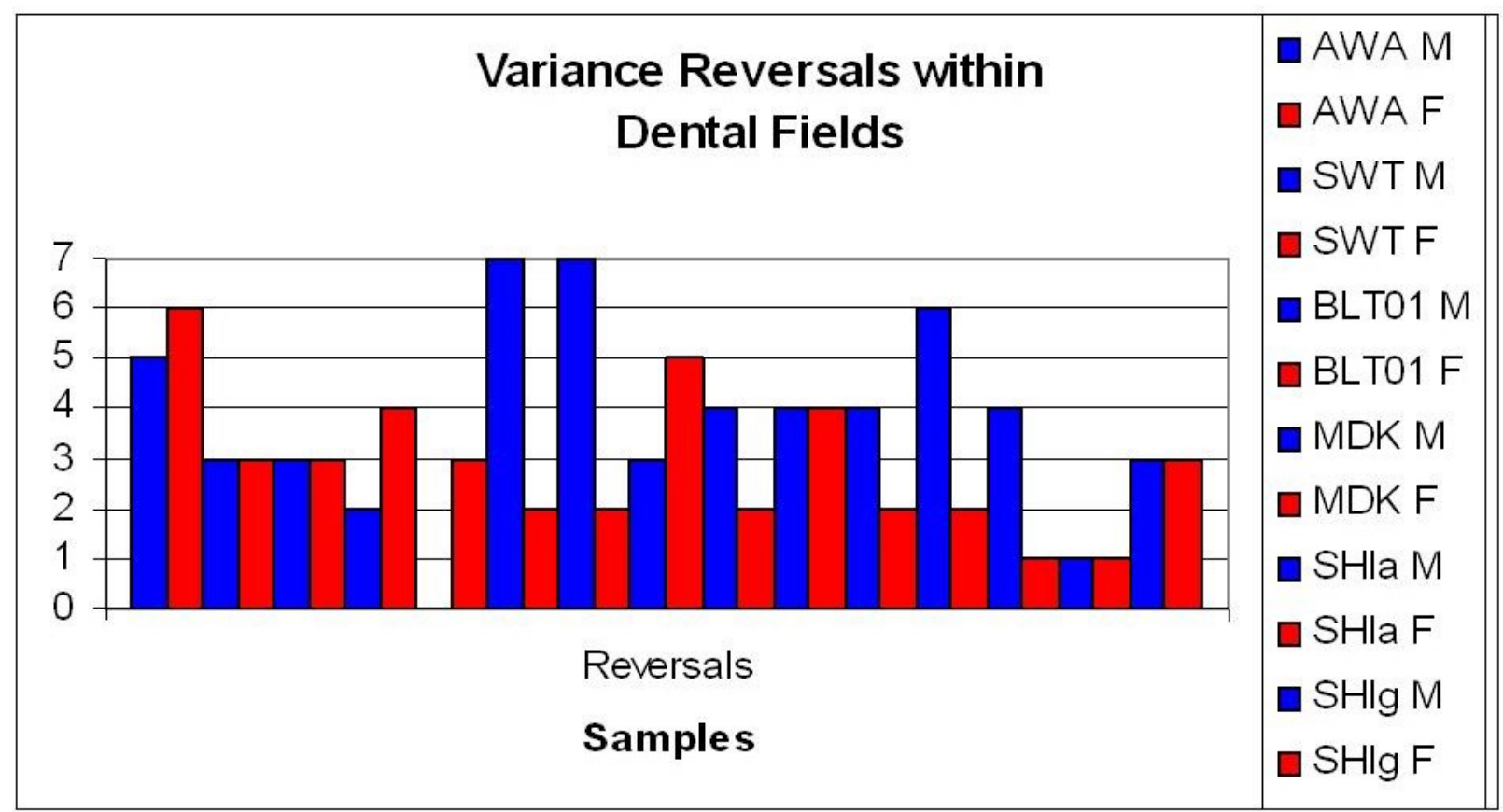

Fig. 6. Number of dental fields in which there is a reversal in the amount of variance expressed by key and distal members.

dental field contributes substantially $(15.5 \%$ $23.1 \%$ ) to the determination of tooth size (Fig. 4), but when considered by sex across the 15 samples it is also clear this contribution differs markedly in both magnitude and polarity (Fig. 7). A two-way analysis of variance by sample indicates that when sex is added as a second factor, the percentage of variance explained increases between 16.7 to $30.8 \%$, an improvement of $27.2 \%$ over when position is considered alone. The improvement in accounting for the variance in tooth size between key and distal members of a dental field varies widely, from a low of $0.6 \%$ among Awans, to a high of $13.2 \%$ among Wakhis from Sost. Nevertheless, a paired-samples t-test indicates this improvement is statistically significant $(t=2.764 ; p=$ 0.015). Clearly, then, sex, in addition to position, is influential in the determination of relative tooth size between key and distal members within a dental field. However, that influence appears to differ markedly across samples.

Rank ordering is used to illustrate differences among samples in the relative contributions played by sex and by position in the relative size of key and distal members of the same morphogenetic field. Ranks were assigned such that those variables in which sex provides a relatively great contribution to the determination of relative size receive high ranks, while those variables in which sex plays a relatively lesser role receive low ranks. Ranks are plotted for maxillary variables in Figure 8 , while ranks are plotted for mandibular variables in Figure 9.

Two-way ANOVA reveals that the contribution of sex to relative tooth size of key and distal members of dental fields is greatest for the buccolingual breadths of the premolars and molars in the maxillary dentition, as well as the buccolingual breadths of the incisors and mesiodistal lengths of the premolars in the mandibular dentition. By contrast, the contribution of sex is low for the mesiodistal lengths of both maxillary and mandibular incisors. Nevertheless, despite these overall trends, there is considerable variation among the 15 samples in the contribution of sex for the remaining variables. Indeed, variation in the relative contribution of sex appears especially wellmarked for buccolingual breadths of incisors and mesiodistal lengths of premolars in the maxillary dentition, as well as the buccolingual breadths of the incisors and premolars in the mandibular dentition. 


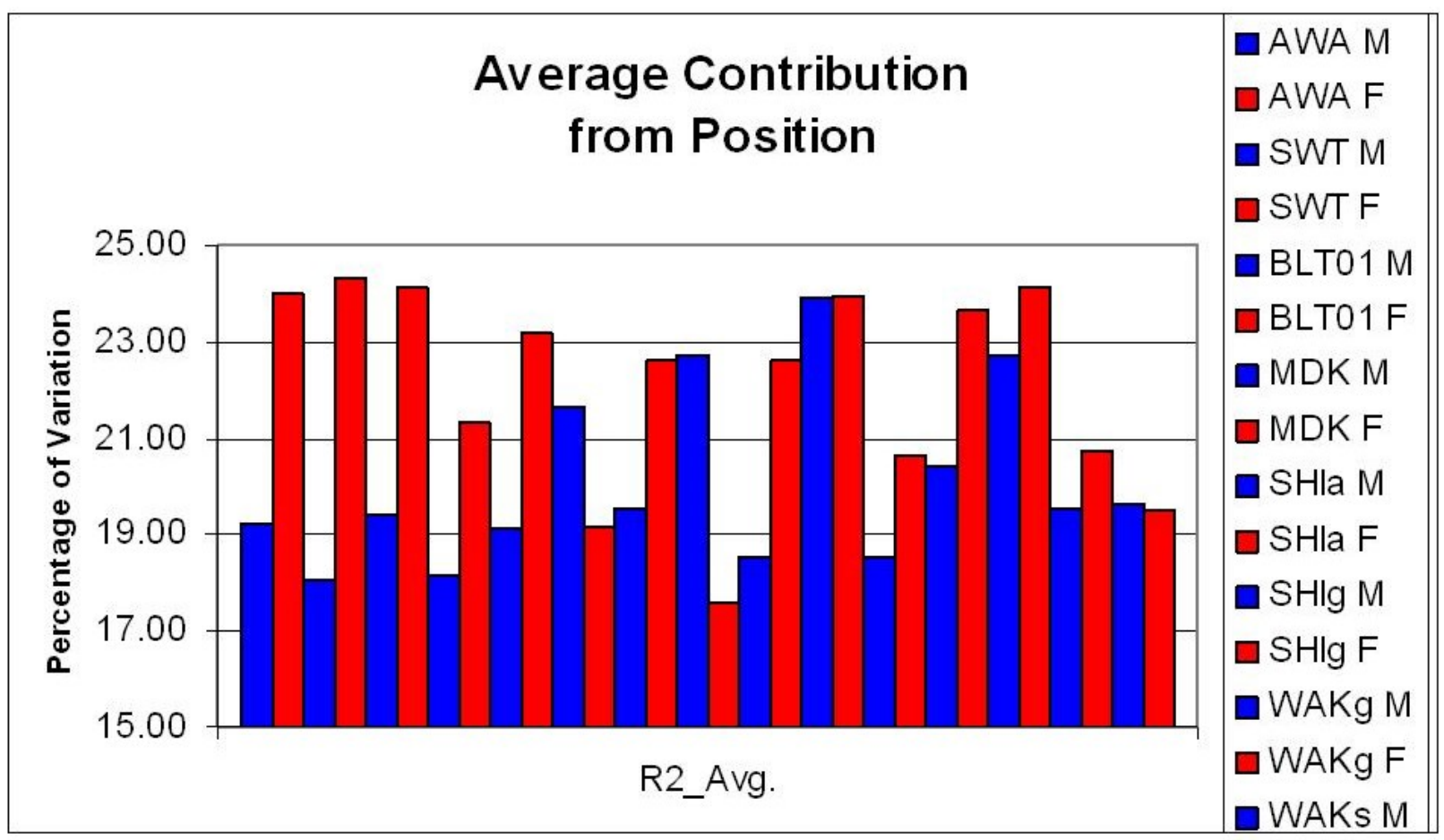

Fig 7. Average contribution by position in accounting for variance in tooth size between key and distal members of a dental field by sex.

\section{Contribution from Sex Maxillary Teeth}

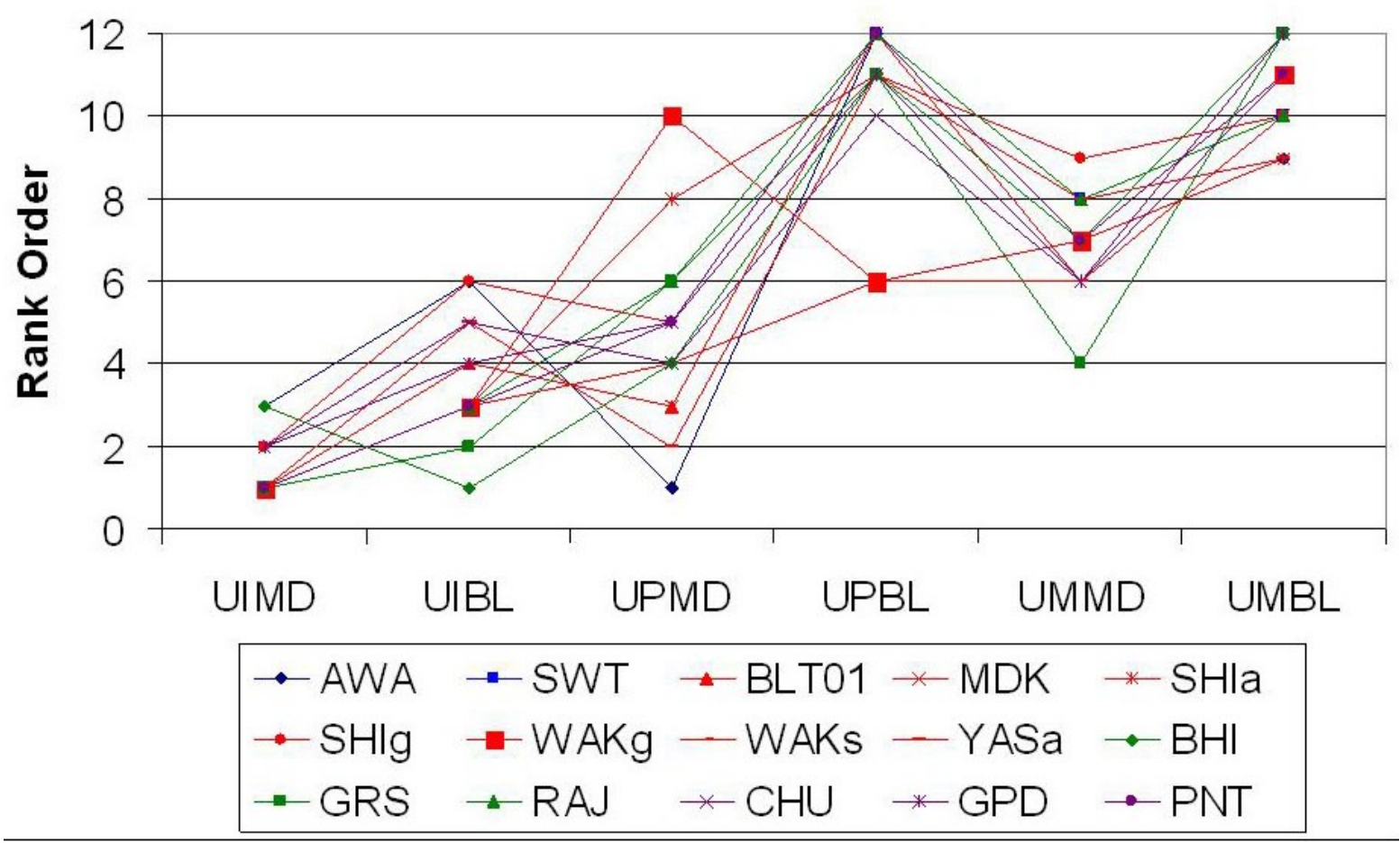

Fig 8. Average relative contribution of sex to position in determination of relative tooth size between key and distal maxillary teeth within a dental field by rank order (ranked by contribution from sex). 
When considered by jaw, variation in the contribution of sex to relative tooth size of key and distal members of the same morphogenetic field among the maxillary teeth varies most among the 15 samples for the mesiodistal lengths of the premolars ( $\mathrm{sd}=2.274$ ), followed by the buccolingual breadths of the premolars ( $\mathrm{sd}=1.988)$ and incisors $(\mathrm{sd}=1.397)$. By contrast, variation in rank order is rather low for the mesiodistal lengths $(\mathrm{sd}=1.223)$ and buccolingual breadths $(\mathrm{sd}=1.060)$ of the molars, while variation among samples is lowest of all for the mesiodistal lengths of the incisors ( $\mathrm{sd}=$ 0.743). Looked at another way, the rank order score for the relative contribution by sex to position for mesiodistal dimension differences between the key and distal members of this morphogenetic field ranges from one among the Awans (where sex contributes the most among the 12 variables considered) to 10 among the Wakhis of Gulmit (where the sex contributes third lowest among the 12 variables considered).

Turning to the mandibular teeth, variation in the contribution of sex to relative tooth size of key and distal members of the same morphogenetic field among the mandibular teeth varies most among the 15 samples for the buccolingual breadths of the premolars ( $\mathrm{sd}=2.000)$, followed by the buccolingual breadths of the incisors ( $\mathrm{sd}=$ 1.668) and the mesiodistal lengths of the molars $(\mathrm{sd}=1.624)$. Variation in rank order is rather low for the buccolingual breadths of the molars (sd= 1.397) and the mesiodistal lengths of the premolars $(\mathrm{sd}=1.187)$, while as in the maxillary arcade, variation is lowest for the mesiodistal lengths of the incisors $(\mathrm{sd}=1.183)$. When the dispersion in rank order scores across samples is considered, the relative sex contribution versus the contribution by position for differences in buccolingual breadths between the key and distal members of the premolars ranges from two among the two Wakhi samples (WAKg, WAKs) to a high of nine among Chenchu tribals of southeastern peninsular India. By contrast, dispersion in mesiodistal lengths of the incisors only ranges from one in three samples (CHU, GPD, SHIg) to five (WAKg).

\section{DISCUSSION}

Question 1: Do Developmental Fields exist such that Variance is Less among "Key" Teeth Relative to "Distal" Teeth?
It has often been maintained that the earlier developing members within a morphogenetic field are less affected by environmental factors than later developing members (Alvesalo and Tigerstedt, 1974; Townsend and Brown, 1980) and this has led some researchers who focus on dental morphology to limit considerations of differential trait frequencies found on key teeth only (Scott and Dahlberg 1982; Scott et al 1983; Sofaer et al 1972; Turner 1976). A recent review by Townsend and co-workers (2009) observes that later developing teeth within a morphogenetic field spend a relatively longer period of time in the soft tissue stage prior to calcification during which epigenetic and environmental factors can influence the shape and size of the crown. A similar observation was made by Keene (1982), whose concept of the morphogenetic triangle emphasized the dynamism in the formation of the individual cusps until coalescence among the cusps fuses them in place. Not surprisingly, given these expectations, it has been widely assumed that the key tooth within each morphogenetic field ought to possess the highest heritabilities, while the non-key teeth ought to be marked by lower heritabilities. Indeed, Alvesalo and Tigerstadt (1974) reported such patterning in their data, but other researchers have been unable to confirm such results (Dempsey and Townsend, 2001).

With sexes pooled, only one out of four contrasts of variance between key and distal members within dental fields are significantly heterogeneous, but the overwhelming majority that are significant are due to much higher variance among distal members. While such findings corroborate dental field theory and the findings of other researchers (Harris \& Nweeia 1980; Herskovitz et al. 1993; Kieser \& Groeneveld 1998; Mayhall \& Saunders 1986), it is also the case that one in four contrasts yields higher variance for the key tooth than for the distal tooth within a dental field. A large number of these reversals occur among the mandibular incisors, suggesting that Dahlberg's (1945, 1951) insistence on a reversal of the dental field among mandibular incisors is incorrect. In contrast to expectations of the theory of compensatory tooth size effect (Sofaer 1973; Sofaer et al, 1972a,b), as well as the findings of some researchers with regard to bilateral asymmetry (Harris \& Nweeia 1980; Townsend \& Brown 1980), no predilection for increased variance was found for mesiodistal 
over buccolingual dimensions or vice versa. Indeed, one-way ANOVA indicates that position within a dental field only contributes about onefifth of the percentage of variance explained in tooth size.

Taken together, such results weaken considerably an orthodox application of Butler's field theory. As noted by Townsend et al. (2009), a complicated array of epigenetic and morphogenetic events appears to be involved at different times and to various degrees in crown formation. Further, given more recent research which indicates that secondary enamel knot formation determines the location of cusp tips (Jernvall et al., 1994; Matalova et al., 2005), that knot positioning relative to the margin of the occlusal surface (Moorman et al., 2013) and overall crown size are related to such morphological features of the permanent tooth crown as Carabelli's trait (Harris, 2007), it is clear that crown size and shape are phenomena whose interrelatedness are poorly captured by simplistic developmental models that rely upon morphogenetic fields with key and distal members.

\section{Question 2: Are Females more Genetically Canalized than Males?}

The assertion that among humans males are less buffered against environmental stress than females can be traced to Greulich's (1951) study of growth and development among children on the island of Guam who suffered from nutritional stress and other deprivations during World War II. Greulich found than Guamanian boys suffered greater shortfalls in height, weight, weight for height and skeletal maturation than girls when compared to well-nourished U.S. children. Similar results were found among children who survived the atomic bombing of Hiroshima and Nagasaki (Gruelich et al., 1953), as well as children exposed to radiation caused by nuclear testing in the Marshall Islands (Sutow et al., 1965).

In 1969, Stini examined the impacts of malnutrition upon growth and development among boys and girls of Helconia, Colombia. He found skeletal maturation to be delayed in all malnourished children early in life. However, skeletal age among girls was closer to U.S. standards in the earliest years of life and the differences in skeletal maturity between boys and girls increased throughout adolescence such that girls experienced a form of "catch-up" growth to U.S. standards while similar- ly malnourished boys failed to do so resulting in a reduction of "blunting" of sex dimorphism (Dettwyler, 1992; Eveleth, 1975; Leonard, 1991; Stini, 1972; Tobias, 1972). Similar results have been obtained in studies of the impact of high altitude upon growth and development among Andean populations (Frisancho and Baker, 1970; Pawson, 1977; Stinson, 1980), as well as sex differences in response to infectious diseases (Stini, 1985), parasite loads (Brabin, 1990), and famine (Grayson, 1990). Stini $(1975,1982,1985)$ suggested that such sex differences may be the consequence of selection for better environmental buffering in females because of their greater investment in reproduction in supporting pregnancy, lactation and child rearing.

Turning to odontometric variation within the permanent dentition and given the expectations of dental field theory, males ought to express a lesser degree of genetic canalization by exhibiting greater variance among distal members of a morphogenetic field relative to key members. That is, the lesser degree of buffering against environmental perturbations ought to more often result in levels of variance among key and distal teeth that are statistically different. Further, because of lesser buffering and hence greater variation among distal teeth within a morphogenetic field, reversals in levels of variance among key and distal members of the same morphogenetic field ought to be few. By contrast, among females the greater amount of buffering should reduce the relative amount of variance found among the distal members of a morphogenetic field and thereby result in fewer instances in which the levels of variance between key and distal members of a morphogenetic field are significantly heterogeneous. A secondary consequence of greater buffering among females is that greater parity in variance among key and distal members of a morphogenetic field is that reversals ought to be more common due to random chance.

Running contrary to expectations, Bartlett's chi-square indicates that males are marked by a fewer number of dental fields with significant heterogeneous levels of variance between key and distal members, for significant heterogeneity occurs in only three of the 15 samples $(20.0 \%)$, while females are marked by equivalent or higher numbers of reversals in 12 of the 15 samples $(80.0 \%)$. When heterogeneity of variance is considered by 
dental field across all samples, Bartlett's chisquare identifies 68 contrasts as exhibiting significantly heterogeneous levels of variance. Once again running contrary to expectations, males do not exhibit a pattern in which they are affected far more often than females. Instead, with 35 and 33 significant differences affecting males and females, respectively, it appears that members of both sexes are equally buffered against environmental perturbations that affect odontogenesis.

As noted above, an examination of the patterning of variance among key and distal teeth within dental fields finds that a little more than one-fourth $(99 / 360=27.5 \%)$ are marked by a reversal in which variance is greater among key teeth than their distal counterparts. Males are more often affected than females, but when considered by sample, reversal prevalence is equivalent or greater among females than males in nine of the 15 samples. Taken together, these results offer only tepid support for the contention that females are more highly genetically canalized and hence odontogenesis is less affected by environmental factors among females than are males. These finding corroborate those of other researchers who find similar levels of postnatal variability in growth and development among members of both sexes (Frisancho et al., 1980; Martorell et al., 1975, 1984; Stinson, 1985; Yarborough et al., 1975) as well in linear enamel hypoplasia prevalence (Angel et al., 1987; Goodman et al., 1987, 1991; Manzi et al., 1999; May et al., 1993; Santos and Coimbra, 1999; Zhou and Corruccini, 1998). However, as noted by Guatelli-Steinberg and Lukacs (1999), indicators of postnatal stress offer a mixed signal concerning sex differences in response to stress. This is because cultural factors may outweigh and obfuscate the actual levels of stress experienced. Thus, the evidence found here for equivalent levels of variability for males and females may be the consequence of cultural factors that favor care, treatment and feeding of boys over girls. Thus, with regard to greater developmental canalization of females over males, it is clear that if such canalization exists it is not of a sufficient degree to be expressed consistently across the samples analyzed here. Consequently, one cannot assume that females will be less variable odontometrically than their male counterparts.

\section{Question 3: Is Sex Dimorphism Uniformly Ex- pressed across Adequately Nourished Human Populations?}

Teeth are considered a useful means for determination of sex (Ghose and Baghdady, 1979; Harris and Nweeia, 1980; Potter et al., 1981; Iscan and Kedici, 2003), especially in cases where remains are highly fragmentary (Anuthama et al., 2011; Prabhu and Acharya, 2009; Vodanovic et al., 2006).

It is usually the case that the canines are the most dimorphic teeth in the permanent dentition (Acharya and Mainali S., 2007; Garn et al., 1967; Iscan and Kedici, 2003; Lund and Mörnstad, 1999; Potter et al., 1981; Townsend and Brown, 1979), but some studies report that other teeth are either the most dimorphic (Garn et al., 1966; Shrestha, 2005) or nearly as dimorphic as the canine in certain populations (Iscan and Kedici, 2003; Kieser and Groeneveld, 1989; Perzigian, 1976; Potter 1972; Potter et al., 1981; Sharma 1983). Indeed, some studies have reported the presence of "reverse dimorphism" in which females possess larger averages for certain variables than males (Acharya and Mainali, 2007; Ghose and Baghdady, 1979; Harris and Nweeia, 1980; Prabhu and Acharya, 2009). In fact, Ghose and Baghdady (1979) report that fully one-third of the variables they examined among Yemenites exhibit such "reverse dimorphism."

Numerous studies report population differences in both the patterning (Anuthama et al., 2011; Ates et al., 2006; Iscan and Kedici, 2003; Prabhu and Acharya, 2009) and magnitude (Anuthama et al., 2011; Iscan and Kedici, 2003; Prabhu and Acharya, 2009) of sex dimorphism in odontometric variables. Such differences also extend to the relative size of key versus distal members of the same morphogenetic field. Designating such differences as "tooth size crown gradients," Harris and Harris (2007) found marked differences between major human groups in which some are marked by "steep" gradients of sharp reductions in size from the key to distal teeth, while others possess "shallow" gradients with similar dimensions across the members of a field.

One-way ANOVA demonstrated that among the 15 samples considered here a tooth's position within a dental field accounts for $15.5 \%$ to $23.1 \%$ of the observed variation in tooth size within morphogenetic fields. Yet, it is also the case that when 


\section{Contribution from Sex Mandibular Teeth}

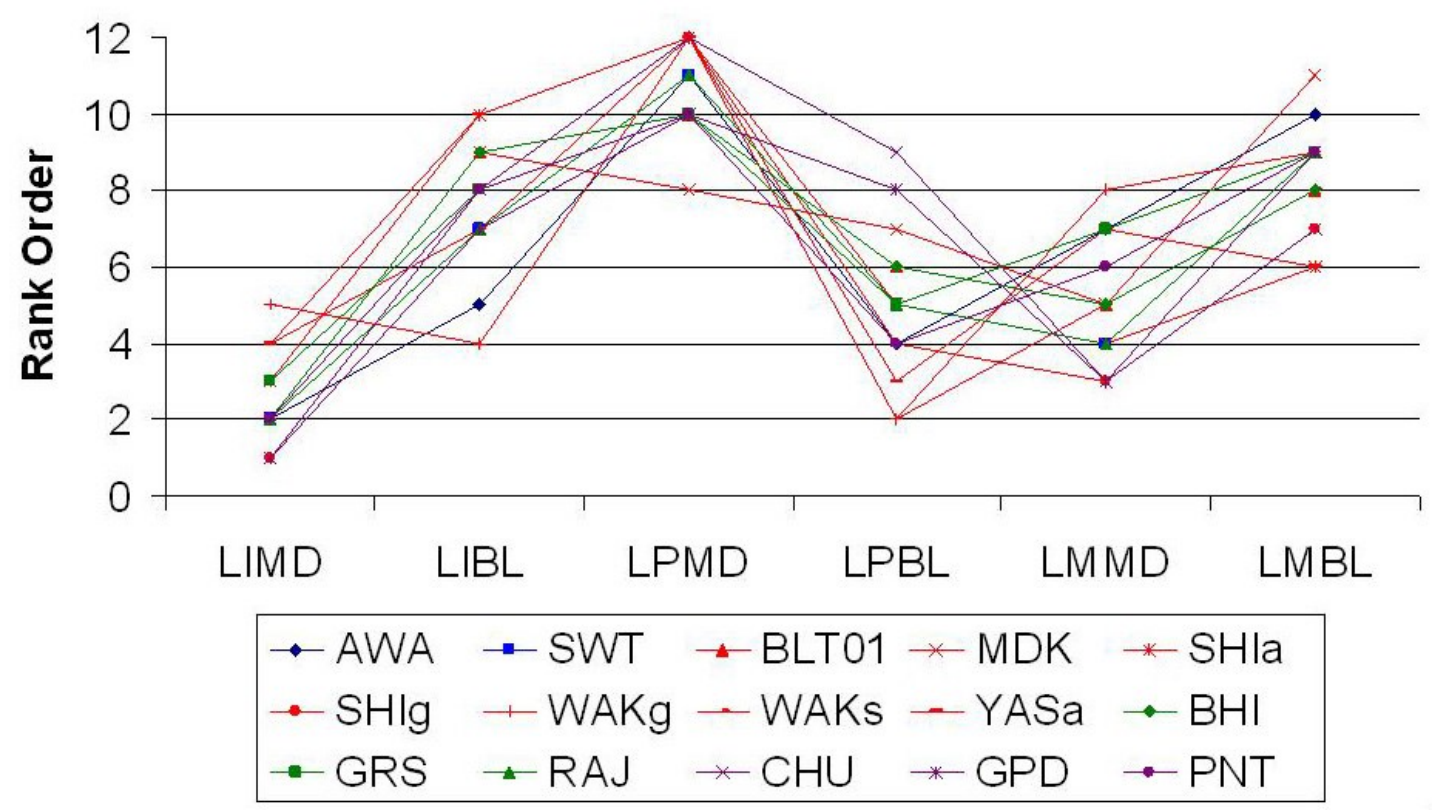

Fig 9. Average relative contribution of sex to position in determination of relative tooth size between key and distal mandibular teeth within a dental field by rank order (ranked by contribution from sex).

variation within dental fields is considered by sex it is clear the contribution from sex differs markedly with regard to both magnitude and polarity. A two-way analysis of variance by sample revealed that when sex is added as a second factor, the percentage of variance explained increases to $16.7 \%$ $30.8 \%$, which is an improvement of $27.2 \%$ when consideration is limited to position within a morphogenetic field. In accordance with the observations of Harris and Harris (2007), the improvement in accounting for the variance in tooth size between key and distal members of a dental field varies widely. Thus, not only does it appear that sex, in addition to position, is influential in the determination of relative tooth size between key and distal members within a dental field, it is also the case that this influence differs markedly across samples. Such differences in the expression of sex dimorphism were found to mirror differences in tooth size allocation as a whole (Hemphill, 1991) and also explain why discriminant functions developed for determination of sex in one population often predict sex with much lower accuracy when applied to members of other populations (Wright and Hemphill, 2012).

\section{CONCLUSION}

Viewed as a whole, this "fool's mission" appears not to have been at all foolish. Dental field theory offers an inaccurate picture of the true pattern of variation among key and distal members of morphogenetic fields. For while it is the case that key teeth are often less variable than their distal counterparts, reversals are common. Dahlberg's $(1945,1951)$ alleged reversal of polarity among mandibular incisors is not supported, nor is Sofaer's (1973; Sofaer et al, 1972a,b) notion of compensatory tooth size effect. The notion that females tend to be more highly genetically canalized than males and hence are more resistant to environmental perturbations is not confirmed. Males and females were found to exhibit similar levels of relative variability between key and distal members of morphogenetic fields. However, since much of the development of the permanent tooth crown occurs post-natally, potential mitigating cultural factors that favor males over females cannot be ruled out. There is abundant evidence that sex dimorphism is expressed differently, both with regard to patterning and to magnitude across hu- 
man populations. Drawing from Harris and Harris' (2007) notion of tooth crown size gradients within morphogenetic fields it is clear that among the South Asian ethnic groups considered here, there is considerable variation in the expression of sex dimorphism. Indeed, the very low expression of sex dimorphism among the relatively wellnourished Awans of Mansehra District coupled with the marked expression of sex dimorphism among the isolated high altitude Wakhis of Sost, suggest strongly that these differences cannot be attributed to mere environmentally induced "blunting" of sex dimorphism. Instead, these differences in the degree and patterning of sex dimorphism in permanent tooth size are the consequence of the same population-specific differences in the array of genes that control the apportionment of overall tooth size throughout the permanent dentition. Given that population differences in the expression of sex dimorphism in permanent tooth size are even less likely to be subject to the impacts of natural selection than overall tooth size, patterning in the expression of sex dimorphism in permanent tooth size offers an additional avenue for unraveling the complex histories of human populations on local, regional and continental levels.

\section{LITERATURE CITED}

Acharya AB, Mainali S. 2007. Univariate sex dimorphism in the Nepalese dentition and the use of discriminant functions in gender assessment. Forensic Sci Int 137:160-164.

Alvesalo L, Tigerstedt PMA. 1974. Heritabilities of human tooth dimensions. Heriditas 77:311-318.

Angel JL, Kelley JO, Parrington M, Pinter S. 1987. Life stresses of the free Black community as represented by the First African Baptist Church, Philadelphia 1823-1841. Am J Phys Anthropol 74:213-229.

Anuthama K, Shankar S, Ilayaraja V, Kumar GS, Rajmohan M, Vignesh. 2011. Determining dental sex dimorphism in South Indians using discriminant function analysis. For Sci Internat 212:86-89.

Ates M, Karaman F, Iscan MY, Erdem TL. 2006. Sexual differences in Turkish dentition. Legal Med 8:288-292.

Brabin L. 1990. Factors affecting the differential susceptibility of males and females to onchocerciasis. Acta Leiden 59(1/2):413-426.

Butler PM. 1939. Studies on the mammalian denti- tion: differentiation of the post-canine dentition. Proc Zool Soc London 109B: 1-36.

Dahlberg AA. 1945. The changing dentition of man. J Dent Res 16: 59-62.

Dahlberg AA. 1951. The dentition of the American Indian. In: Laughlin WS, editor. Papers on the physical anthropology of the American Indian. New York: Viking Fund. p 138-176.

Dempsey PJ, Townsend GC. 2001. Genetic and Environmental contributions to variations in human tooth size. Heredity 86:685-693.

Dempster AP, Laird NM, Rubin DB. 1977. Maximum likelihood from incomplete data via the EM algorithm. J Roy Stat Soc Ser B39(1):1-38.

Dettwyler KA. 1992. Nutritional status of adults in rural Mali. Am J Phys Anthropol 88(3):309-321.

Eveleth PB. 1975. Differences between ethnic groups in sex dimorphism of adult height. Ann Hum Biol 2(1):35-39.

Frisancho AR, Baker PT. 1970. Altitude and growth: a study of the patterns of physical growth of a high altitude Peruvian Quechua population. Am J Phys Anthropol 32:279-292.

Frisancho AR, Guire K, Babler W, Borkan G, Way A. 1980. Nutritional influence on childhood development and genetic control of adolescent growth of Quechua and Mestizos from the Peruvian lowlands. Am J Phys Anthropol 52:367-375.

Garn SM, Lewis AB, Kerewsky RS. 1965. Genetic, nutritional, and maturational correlates of dental development. J Dent Res 44: 228-242.

Garn SM, Lewis AB, Kerewsky RS. 1966. The meaning of bilateral asymmetry in the permanent dentition. Angle Orthodont 36: 55-62.

Garn SM, Lewis AB, Swindler DR, Kerewsky RS. 1967. Genetic control of sexual dimorphism in tooth size. J Dent Res 46(Suppl 5):963-972.

Ghose LJ, Baghdady VS. 1979. Analysis of the Iraqi dentition: mesiodistal crown diameters of permanent teeth. J Dent Res 58:1047-1054.

Goodman AH, Allen LH, Hernandez GP, Amador A, Arriola LV, Chavez A, Pelto GH. 1987. Prevalence and age at development of enamel hypoplasia in Mexican children. Am J Phys Anthropol 72:7-19.

Goodman AH, Martinez C, Chavez A. 1991. Nutritional supplementation in the development of linear enamel hypoplasias in children from Tezonteopan, Mexico. Am J Clin Nutr 53:773-781.

Grayson DK. 1990. Donner Party deaths: a demographic assessment. J Anthropol Res 46(3):223242. 
Gruelich WW. 1951. The growth and developmental status of Guamanian school children in 1947. Am J Phys Anthropol 9:55-70.

Gruelich WW, Crimson CS, Turner ML. 1953. The physical growth and development of children who survived the atomic bombing of Hiroshima or Nagasaki. J Pediatr 43:121-145.

Guatelli-Steinberg D, Lukacs JR. 1999. Interpreting sex differences in enamel hypoplasia in human and non-human primates: developmental, environmental, and cultural considerations. Yrbk Phys Anthropol 42:73-126.

Harris EF. 2007. Carabelli's trait and tooth size of human maxillary first molars. Am J Phys Anthropol 132:238-246.

Harris EF, Harris JT. Racial differences in tooth crown size gradients within morphogenetic fields. Rev Estomatol 15(2) Suppl 1:7-16.

Harris EF, Nweeia MT. 1980. Tooth size of Ticuna Indians, Columbia, with phenetic comparisons to other Amerindians. Am J Phys Anthropol 53:81-91.

Hemphill BE. 1991. Tooth size apportionment among contemporary Indians: factors of caste, language, and geography. Unpublished Ph.D. dissertation, University of Oregon, Eugene.

Hershkovitz I, Livshits G, Moskona D, Arensburg B, Koblyiansky E. 1993. Variables affecting dental fluctuating asymmetry in human isolates. Am J Phys Anthropol 91(3):349-35.

Iscan MY, Kedici PS. 2003. Sexual variation in buccolingual dimensions in Turkish dentition. For Sci Intl 137:160-164.

Jernvall J, Kettunen P, Karavanova I, Martin LB, Thesleff I. 1994. Evidence for the role of the enamel knot as a control center in mammalian tooth cusp formation: non-dividing cells express growth stimulating Fgf-4 gene. Intl J Dev Biol 38:463-469.

Keene HJ. 1982. The morphogenetic triangle: a new conceptual tool for application to problems in dental morphogenesis. Am J Phys Anthropol 59:281-287.

Kieser J, Groeneveld H. 1989. The unreliability of sex allocation based on human odontometric data. J For Odontostomatol 7:1-12.

Kieser JA, Groeneveld HT. 1998. Fluctuating dental asymmetry and prenatal exposure to tobacco smoke. In: Lukacs JR, Editor. Human dental development, morphology and pathology: A tribute to Albert A. Dahlberg. University of Oregon
Anthropology Paper 54. p 287-297.

Kieser JA, Groeneveld HT, Preston CB, 1985. An odontometric analysis of the Lengua Indians dentition. Hum Biol 57:611-620.

Leonard WR. 1991. Age and sex differences in the impact of seasonal energy stress among Andean agriculturalists. Hum Ecol 19(3):351-368.

Lund H, Mörnstad H. 1999. Gender determination by odontometrics in a Swedish population. J Forensic Odontostomatol 17:30-34.

Manzi G, Salvadei L, Vienna A, Passarello P. 1999. Discontinuity of life conditions at the transition from the Roman imperial age to the early middle ages: Example from central Italy evaluated by pathological dentoalveolar lesions. Am J Hum Biol 11(3):327-341.

Martorell R, Habicht J-P, Yarborough C, Lechtig A, Klein RE, Western KA. 1975. Acute morbidity and physical growth in rural Guatamalan children. Am J Phys Anthropol Am J Dis Child 129:1296-1301.

Martorell R, Leslie J, Moock PR. 1984. Characteristics and determinants of child nutritional status in Nepal. Am J Clin Nutr 39:74-86.

Matalova E, Antonarakis GS, Sharpe PT, Tucker AS. 2005. Cell lineage of primary and secondary enamel knots Dev Dyn 233:754-759.

May RL, Goodman AH, Meindl RS. 1993. Response of bone and enamel formation to nutritional supplementation and morbidity among malnourished Guatamalan children. Am J Phys Anthropol 92:37-51.

Mayhall JT, Saunders SR. 1986.Dimensional and discrete dental trait asymmetry relationships. Am J Phys Anthropol 69(3):403-411.

Moorman S, Guatelli-Steinberg D, Hunter J. 2013. Metamerism, morphogenesis, and the expression of carabelli and other dental traits in humans. Am J Phys Anthropol 150(3):400-408.

Moorrees CFA (1957) The Aleut dentition. Cambridge: Harvard University Press.

Nichol CR, Turner II CG, Dahlberg AA. 1984. Variation in the convexity of the human maxillary incisor labial surface. Am J Phys Anthropol 63: 361-370.

Niswander JD, Chung CS. 1965. The effects of inbreeding on tooth size in Japanese children. Am J Hum Genet 17:390-398.

Pawson IG. 1977. Growth characteristics of populations of Tibetan origin in Nepal. Am J Phys Anthropol 47:473-482. 
Perzigian AJ. 1976. The dentition of the Indian Knoll skeletal population: odontometrics and cusp number. Am J Phys Anthropol 44:113-121.

Potter RHY. 1972. Univariate versus multivariate differences in tooth size according to sex. J Dent Res 51:716-722.

Potter RHY, Alcazaren AB, Herbosa FM, Tomaneng J. 1981. Dimensional charactgeristics of the Filipino dentition. Am J Phys Anthropol 55:33-42.

Prabhu S, Acharya AB. 2009. Odontometric sex assessment in Indians. For Sci Intl 192:129e.1129 e.5.

Santos RV, Coimbra CE. 1999. Hardships of contact: enamel hyperplasias in Tupí-Mondé Amerindians from the Brazilian Amazonia. Am J Phys Anthropol 109:111-127.

Sofaer JA. 1973. A model relating developmental interaction and differential evolutionary reduction of tooth size. Evolution 27:427-434.

Scott, GR, Dahlberg AA. 1982. Microdifferentiation in tooth crown morphology among Indians of the American southwest. In: Kurten B, editor. Teeth: form, function and evolution. New York: Columbia University Press. p 259-291.

Scott GR, Potter RHY, Noss JF, Dahlberg AA, Dahlberg T. 1983. The dental morphology of Pima Indians. Am J Phys Anthropol 61:13-31.

Sharma JC. 1983. Dental morphology and odontometry of the Tibetan immigrants. Am J Phys Anthropol 61:495-505.

Snedecor GW, Cochran WG. 1989. Statistical methods. $8^{\text {th }}$ edition. Ames: Iowa State University Press.

Sofaer JA, Niswander JD, MacLean, CJ, Workman PL .1972a. Population studies on southwestern Indian tribes. $\mathrm{V}$. Tooth morphology as an indicator of biological distance. Am J Phys Anthropol 37:357-366.

Sofaer JA, MacLean CJ, Bailit HL. 1972b. Heredity and morphological variation in early and late developing human teeth of the same morphological class. Arch Oral Biol 17:811-816.

Shrestha RM. 2005. Measurement of mesio-distal tooth diameter of Nepalese permanent dentition. J Nepal Dent Assoc 7:55-63.

Stini WA. 1969. Nutritional stress and growth: Sex difference in adaptive response. Am J Phys Anthropol 31:417-426.

Stini WA. 1972. Reduced sexual dimorphism in upper arm muscle circumference associated with protein-deficient diet in a South American population. Am J Phys Anthropol 36:341-352.
Stini WA. 1975. Adaptive strategies of human populations under nutritional stress. In: Watts ES, Johnston FE, Lasker GW, Editors. Biosocial interrelations in population adaptation. The Hague: Mouton. p 19-41.

Stini WA. 1982. Sexual dimorphism and nutrient reserves. In Hall RL, editor, Sexual dimorphism in Homo sapiens. New York: Praeger. p 391-419.

Stini WA. 1985. Growth rates and sexual dimorphism in evolutionary perspective. In: Gilbert RI, Mielke JH, Editors. The analysis of prehistoric diets. Oralndo: Academic Press. p 191-226.

Stinson S. 1980. The physical growth of high altitude Bolivian Aymara children. Am J Phys Anthropol 52:377-385.

Stinson S. 1985. Sex differences in environmental sensitivity during growth and development. Yrbk Phys Anthropol 28:123-147.

Sutow WW, Conrad RA, Griffith KM. 1965. Growth status of children exposed to fallout radiation on Marshall Island. Pediatrics 36:721-731.

Tobias PV. 1982. Growth and stature in South African populations. In Vorster DJM, editor, Human biology of environmental change. London: International Biological Program. p 96-104.

Townsend GC, Brown T. 1979. Tooth size characteristics of Australian aboriginals. Occ Pap Hum Biol 1:17-38.

Townsend GC, Brown T. 1980. Dental asymmetry in Australian aboriginals. Hum Biol 52:661-673.

Townsend G, Harris EF, Lesot H, Clauss F, Brook A. 2009. Morphogenetic fields within the human dentition: A new, clinically relevant synthesis of an old concept. Arch Oral Biol 54s:s34-s44.

Turner II CG .1976. Dental evidence on the origins of the Ainu and the Japanese. Science 193:911913.

Yarborough C, Habicht J-P, Malina RM, Lechtig A, Klein RE. 1975. Growth, fatness and leanness in Mexican-American children. Am J Clin Nutr 33:2008-2020.

Vodanovic M, Demo Z, Njemirovskij V, Keros J, Brkic H. 2006. Odontometrics: a useful method for sex determination in an archaeological skeletal population? J Archaeol Sci 34:905-913.

Wright CA, Hemphill BE. 2012. Determination of sex from differences in tooth size in a modern admixed population from New Mexico: relative efficacy or permanent and deciduous teeth. Am J Phys Anthropol (Suppl) 54:306-307.

Zhou L, Corruccini RS. 1998. Enamel hypoplasia related to famine stress in living Chinese. Am J Hum Biol 10:723-733. 